\title{
Médicos de Saúde Pública nos Hospitais: Apenas uma Parte do Futuro
}

\author{
Hospital Based Public Health Doctors: Just a Part of the Future
}

André PERALTA-SANTOS $\rrbracket^{1}$, Bernardo GOMES ${ }^{2}$

Acta Med Port 2015 Nov-Dec;28(6):681-683

Palavras-chave: Educação Profissional em Saúde Pública; Portugal; Saúde Pública/educação.

Keywords: Education, Public Health Professional; Portugal; Public Health/education.

No final do primeiro semestre de 2014 foi divulgado publicamente pelo Diretor Geral da Saúde a intenção de criar Unidades de Saúde Pública (USP) nos hospitais. Contudo, não ficou claro quais as funções a desempenhar por estas unidades e, consequentemente, nem que profissionais seriam os mais adequados para as desempenhar.

No seguimento destas declarações, o Colégio de Saúde Pública da Ordem dos Médicos (CSPOM) publicou um parecer ${ }^{1}$ onde faz considerações acerca do enquadramento dos Médicos de Saúde Pública (MSP) nos hospitais.

Acreditamos que vale a pena não circunscrever a questão à pertinência de ter MSP nos hospitais, situação já equacionada, ${ }^{2}$ mas sim em qual é o valor acrescentado destes, onde estão ou deviam estar posicionados e em que parte do Sistema de Saúde.

\section{A situação atual}

Atualmente a atividade dos mais de 400 MSP está dividida entre as Unidades de Saúde Pública (a esmagadora maioria), estando os restantes distribuídos pelos Departamentos de Saúde Pública das Administrações Regionais de Saúde (DSP), Centros de Vacinação Internacional, Direção Geral da Saúde (DGS) e, em casos excepcionais, noutras instituições (p.e. Instituto Português de Oncologia, Instituto Nacional de Saúde).

A nível das USP, parece existir uma sensação generalizada que existem atividades que não se traduzem nem em ganhos em Saúde para a população, nem correspondem às expectativas dos próprios ou dos outros colegas no terreno. Apesar de não existirem estudos sobre o assunto, esta sensação radicará no fato de parte substancial do trabalho médico em algumas USP estar, presentemente, relacionado com a instrução de Juntas Médicas de Incapacidade, ou outras actividades em que o MSP não está mais habilitado para a sua execução que qualquer outro colega ou outro profissional de Saúde Pública. Por conseguinte, o valor acrescentado da formação médica em Saúde Pública para estas tarefas é diminuto. Contrariamente, em outras áreas como a coordenação da vacinação, vigilância de doenças transmissíveis e não transmissíveis, sanidade internacional, administração da saúde e avaliação do impacte do funcionamento dos serviços de saúde na saúde da população, gestão de programas de saúde ou promoção da saúde, o MSP tem um valor acrescentado, podendo ainda ser aprofundado.

Podemos, então, inferir que estamos a desperdiçar parcialmente o investimento que a sociedade faz na formação do MSP, a perder oportunidades para o Sistema de Saúde, tendo também como resultado uma dissonância entre a formação médica e a prática em Saúde Pública.

Não se assistiu nas USP ao mesmo fenómeno que se assistiu com as Unidades de Saúde Familiar (USF). Não existiu reforço de recursos humanos e logísticos, atribuição de incentivos a quem trabalha melhor ou liberdade de constituição de equipas. Assim, assistimos a várias USP com poucos profissionais, mal equipadas e na maioria dos casos com uma contratualização muito incipiente.

O modelo de USP por Agrupamento de Centros de Saúde ainda não atingiu o seu pleno desenvolvimento. Será que não é uma aposta do Serviço Nacional de Saúde?

\section{O lugar do Médico de Saúde Pública no século XXI}

Existem várias perspectivas europeias da formação e desempenho dos Médicos de Saúde Pública. A título de exemplo, realçamos França, Espanha e Reino Unido.

Em França, o posicionamento de referência do MSP é hospitalar e com um forte componente académico. ${ }^{3}$ Estes profissionais geram conhecimento com aplicação imediata em diversos níveis como o controlo de infecção, estudos custo-efectividade, epidemiologia de doenças transmissíveis e doenças crónicas.

A carteira de serviços dos especialistas em Espanha (Medicina Preventiva y Salud Publica) refere competências com relação estreita com os hospitais com destaque para o controlo de infecção, vigilância epidemiológica e saúde ocupacional. ${ }^{4}$

No Reino Unido, os MSP podem desempenhar funções nos diversos níveis de cuidados, incluindo os serviços

\footnotetext{
1. Unidade de Saúde Pública da Amadora. Amadora. Portugal.

2. Unidade de Saúde Pública do Agrupamento de Centros de Saúde Entre Douro e Vouga I. Santa Maria da Feira. Portugal.

$\triangle$ Autor correspondente: André Peralta Santos. andre.peralta.santos@gmail.com

Recebido: 22 de Outubro de 2014 - Aceite: 19 de Maio de 2015 | Copyright $\odot$ Ordem dos Médicos 2015
} 
locais de Saúde Pública, destacando papéis de consultadoria e liderança nos processos de decisão em Saúde. ${ }^{5}$

Não pretendemos favorecer uma perspectiva em particular mas podemos, a partir destes exemplos, conceptualizar mudanças e, consequentemente, enumerar os lugares no Sistema de Saúde que podem maximizar a formação do MSP.

Consideramos como premissa que a Especialidade de Saúde Pública deve, na nossa opinião, funcionar como uma especialidade multidisciplinar, com uma perspectiva populacional, promotora de articulação entre instituições e de maior eficiência dos diferentes níveis de cuidados. Assim sendo, deveria incentivar-se a presença, devidamente articulada, de MSP não só em cuidados de saúde primários mas também por outras instituições chave do Sistema de Saúde para além da DGS e ARS, entre as quais se incluem Instituto Português do Sangue e da Transplantação, Instituto Português de Oncologia, Hospitais, Infarmed, Serviços Partilhados do Ministério da Saúde, etc, tal como preconizado pelo CSPOM.

No entanto, para que esta distribuição seja possível, é necessário que seja reconhecido valor acrescentado pelos MSP às diversas instituições acima enumeradas. Claramente, só é possível mudar o paradigma com o apoio das diversas entidades envolvidas (Ministério da Saúde, Direção Geral da Saúde, direções das instituições e Ordem dos Médicos) de modo a construir uma rede de articulação e valorização do MSP.

A nível Europeu a discussão do papel da Saúde Pública encontra eco no European Action Plan for Strengthening Public Health Services and Capacity, ${ }^{6}$ promovido pela Organização Mundial de Saúde e enquadrado na estratégia Health 2020.

\section{Os desafios para o futuro}

Por último, recordemos os constrangimentos à potencial maximização do valor acrescentado do MSP para o Sistema de Saúde.

O primeiro, e mais importante, é o envelhecimento da especialidade de Saúde Pública - em 2011, 87\% dos especialistas tinha mais de 50 anos $^{7}$ - fenómeno alimentado por uma elevada taxa de desistência da especialidade. Este gap geracional torna as mudanças no perfil da especialidade mais difíceis de concretizar, agravado pela falta de especialistas a assegurar funções nas USP, sobretudo se for pretendido alargar a abrangência da especialidade.

Em segundo lugar, uma alteração do posicionamento do MSP requer uma mudança de mentalidade, não só da maioria das instituições do Sistema de Saúde, tendencialmente conservadoras à mudança, como também dos próprios MSP. A mudança de local de trabalho, a necessidade de articulação com diversas estruturas e a necessidade de demonstrar uma mais-valia para a instituição a curto/ médio prazo requerem uma disponibilidade, capacidade de empenho, competências permanentemente actualizadas e resiliência assinaláveis.

Em terceiro lugar, a diáspora de MSP por outras instituições fora dos cuidados de saúde primários criará novas necessidades de formação específicas, que podem não ter feito necessariamente parte da formação base durante o internato ou da prática profissional regular. É necessário que a formação contínua e especialização na área desejada sejam contempladas pelas instituições que recebem os MSP e/ou por outras entidades com competência e interesse nesse investimento.

Assinalamos, no entanto, que o novo posicionamento dos MSP não deve relegar para segundo plano o nível local, sob risco de se perder uma oportunidade de promover a integração de níveis de cuidados, assegurar a translação de Programas Nacionais, tendo em conta as prioridades de saúde locais e o envolvimento da respectiva comunidade.

\section{CONCLUSÃO}

A criação de Unidades de Saúde Pública nos hospitais encerra inúmeros desafios, mas, na nossa opinião, terão um impacto benéfico para os utentes, para os hospitais e para todo o Sistema de Saúde.

Urge repensar as atividades das USP e o papel que deve ser pedido aos MSP, reflectindo de que forma a formação médica específica em saúde pública terá maior valor acrescentado. Propomos que se aproveite este momento para reflectir sobre o posicionamento e papel dos MSP, não só nos Hospitais mas em outras instituições. Dessa forma, poder-se-á maximizar o potencial dos MSP e, também, rentabilizar outros perfis de formação.

Instamos todos os especialistas em saúde pública, internos e outros colegas a contribuírem para esta discussão, com a certeza que o futuro Sistema de Saúde em Portugal encerra muitos desafios, em que os MSP podem fazer parte da solução.

\section{NOTA DOS AUTORES}

Este artigo foi aceite para publicação a 19 de maio de 2015. A 24 de junho de 2015 foi publicado o Despacho (extrato) n. ${ }^{\circ} 7216 / 2015$, que estabelece a criação dos Serviços de Investigação, Epidemiologia Clínica e de Saúde Pública Hospitalar. Os autores e os editores decidiram manter o artigo como originalmente aceite, pois os pressupostos e argumentos apresentados mantêm-se.

\section{CONFLITOS DE INTERESSE}

Os autores declaram não ter qualquer conflito de interesse relativamente ao presente artigo.

\section{FONTES DE FINANCIAMENTO}

Os autores não obtiveram qualquer fonte de financiamento, subsidio ou bolsa para este trabalho. 


\section{REFERÊNCIAS}

1. Colégio da Especialidade de Saúde Pública. Parecer do colégio de saúde pública enviado ao ministério da saúde em 20/junho/2014. 2014. Ordem dos Médicos. [consultado 2014 ago 15]. Disponível em: https:// www.ordemdosmedicos.pt/?lop $=$ conteudo \&op $=4 \mathrm{c} 27 \mathrm{cea} 8526 \mathrm{af} 8 \mathrm{cfee} 3 \mathrm{~b}$ e5e183ac9605\&id=416849da96fb73bee793e2bf65ae43ac

2. Wright J, Franks A, Ayers P, Jones K, Roberts T, Whitty P. Public health in hospitals: the missing link in health improvement. J Public Health Med. 2002;24:152-5.

3. Conseil National des Universités, College Universitaire des Enseignants de Sante Publique, College d'Enseignants d'Informatique medicale, Biomathematiques, Methodes en epidemiologie et statistiques, College de Liaison des Internes de Sante Publique. Diplôme d'Etudes Spécialisées en Santé Publique et Médecine Sociale. 2013. [consultado 2014 ago 16]. Disponível em: http://files.clisp.fr/formations/ Referentiel\%20formation\%20DES\%20-\%202014.pdf

4. Subdirección General de Planificación e Información Sanitaria, S.E.M.P.S.P. e Higiene. Cartera de Servicios - Especialidade Medicina Preventiva y Salud Pública [consultado 2014 ago 30]. Disponível em: http://www.sempsph.com/es/documentos-sempsph/cartera-serviciosespecialidad

5. Local Government Association, Training of Public Health Specialty Registrars - a guide for local councils. 2013. [consultado 2014 ago 16]. Disponível em: http://www.local.gov.uk/documents/10180/12075/L13861_PH+Trainees+in+LG+final_V4.1.pdf/d805bcef-51de-40fc-a5e20179̄9d2672ae

6. World Health Organization. Strengthening public health services across the European Region - a summary of background documents for the European Action Plan. 2012. WHO. [consultado 2014 ago 20]. Disponível em: http://www.euro.who.int/_data/assets/pdf_file/0017/172016/RC62id05-final-Eng.pdf?ua=1

7. Santana $P$, Peixoto $H$. Estudo de evolução prospectiva de médicos no sistema nacional de saúde. Universidade de Coimbra. 2013. [consultado 2014 ago 15]. Disponível em http://www.medicointerno. com/Documentos/Estudo\%20Evolucao\%20Prospectiva\%20Medicos_ Relatorio\%20Final.pdf 


\section{Médicos de Saúde Pública nos Hospitais: Apenas uma Parte do Futuro}

Acta Med Port 2015:28:681-683

Publicado pela Acta Médica Portuguesa, a Revista Científica da Ordem dos Médicos

Av. Almirante Gago Coutinho, 151

1749-084 Lisboa, Portugal.

Tel: +351218428215

E-mail: submissao@actamedicaportuguesa.com

www.actamedicaportuguesa.com

ISSN:0870-399X | e-ISSN: 1646-0758

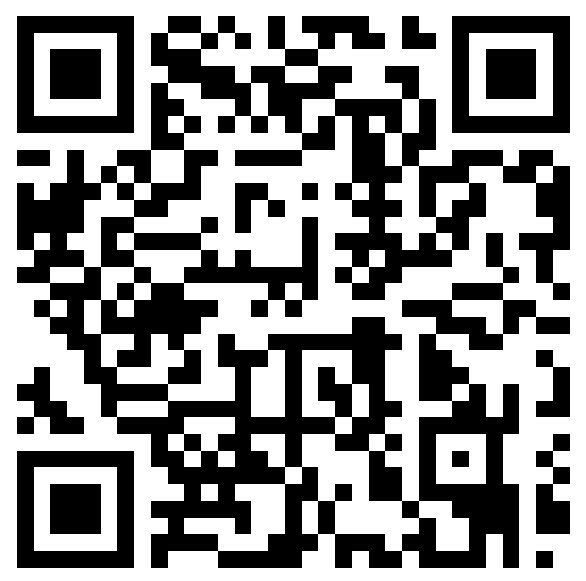

